\title{
Impact of Laurel Wilt, Caused by Raffaelea lauricola, on Leaf Gas Exchange and Xylem Sap Flow in Avocado, Persea americana
}

\author{
Randy C. Ploetz, Bruce Schaffer, Ana I. Vargas, Joshua L. Konkol, Juanpablo Salvatierra, and Ronney Wideman
}

University of Florida, Tropical Research and Education Center, 18905 SW 280th Street, Homestead 33031-3314.

Accepted for publication 24 November 2014.

\begin{abstract}
Ploetz, R. C., Schaffer, B., Vargas, A. I., Konkol, J. L., Salvatierra, J., and Wideman, R. 2015. Impact of laurel wilt, caused by Raffaelea lauricola, on leaf gas exchange and xylem sap flow in avocado, Persea americana. Phytopathology 105:433-440.

Laurel wilt, caused by Raffaelea lauricola, is a destructive disease of avocado (Persea americana). The susceptibility of different cultivars and races was examined previously but more information is needed on how this host responds to the disease. In the present study, net $\mathrm{CO}_{2}$ assimilation $(A)$, stomatal conductance of $\mathrm{H}_{2} \mathrm{O}\left(g_{s}\right)$, transpiration $(E)$, water use efficiency (WUE), and xylem sap flow rates were assessed in cultivars that differed in susceptibility. After artificial inoculation with $R$. lauricola, there was a close relationship between symptom development and reductions in $A, g_{s}$,
\end{abstract}

ABSTRACT

Laurel wilt is a destructive disease that affects members of the Lauraceae plant family (9). It is caused by a fungal symbiont, Raffaelea lauricola (Ophiostomatales), of an Asian ambrosia beetle, Xyleborus glabratus (Scolytinae: Xyleborini) (9), and has killed approximately a half billion native trees in the southeastern United States since 2003 (J. A. Smith, unpublished). By 6 November 2014, the disease had been confirmed as far west as Claiborne County, LA; as far north as Sampson County, NC; and as far south as Miami-Dade County, FL (36) (J. A. Smith, personal communication). Commercial production of an important crop in the family, avocado (Persea americana), is affected in Florida $(23,24)$.

Significant gaps exist in what is known about the host-pathogen interaction and why host plants resist or are susceptible to laurel wilt. Susceptible hosts are quite sensitive, in that as few as 100 conidia of $R$. lauricola are sufficient to initiate the development of lethal disease (10). Yet, even in dead and dying laurel wilt-affected plants, there is scarce to no microscopic evidence of the pathogen (11) (A. Campbell et al., unpublished).

In previous work with 'Simmonds' avocado trees, tyloses, gels, and gums were observed in the xylem of artificially inoculated plants (11). Reduced hydraulic conductivity and xylem function in affected stems was correlated with tylose formation and the development of internal (sapwood discoloration) and external (wilt and leaf necrosis) symptoms of laurel wilt (12). In Simmonds, xylem function was reduced 3 days after inoculation (DAI), well before the development of internal and external symptoms (12).

P. americana is divided into Mexican (M), Guatemalan (G), and West Indian (WI) (also known as Lowland or Antillean) botanical races (14). Hybridization, which occurs freely among the races, is associated with variation in the species (39), and a range of

Corresponding author: R. C. Ploetz; E-mail address: kelly12@ufl.edu

http://dx.doi.org/10.1094/PHYTO-07-14-0196-R

(C) 2015 The American Phytopathological Society
$E$, WUE, and mean daily sap flow in the most susceptible cultivar, 'Russell', and significantly greater disease and lower $A, g_{s}, E$, WUE, and sap flow rates were usually detected after 15 days compared with the more tolerant 'Brogdon' and 'Marcus Pumpkin'. Significant differences in preinoculation $A, g_{s}, E$, and WUE were generally not detected among the cultivars but preinoculation sap flow rates were greater in Russell than in Brogdon and Marcus Pumpkin. Preinoculation sap flow rates and symptom severity for individual trees were correlated at the end of an experiment $(r=0.46)$, indicating that a plant's susceptibility to laurel wilt was related to its ability to conduct water. The potential management of this disease with clonal rootstocks that reduce sap flow rates is discussed.

Additional keywords: hydraulic conductivity, xylem function.

physiological responses to stress is evident (28). For example, differences in tolerance to calcareous soil, salinity, and high or low temperatures are known among the races and their hybrids.

From 2010 to 2012, 24 commercial avocado cultivars of various racial backgrounds were screened for response to laurel wilt in field studies (26). Although immune cultivars were not identified, $\mathrm{G}$ and $\mathrm{M} \times \mathrm{G}$ hybrid cultivars were more tolerant than WI cultivars such as Simmonds. Mechanisms that were associated with the range of host responses that were observed in these trials were not elucidated. For example, the extent to which xylem function influenced symptom development in the different cultivars was not assessed. Better understanding of this relationship could provide insight on the host-pathogen interaction and facilitate the development of laurelwilt-tolerant genotypes of this important fruit crop.

Leaf gas exchange has been used as a sensitive, nondestructive assay of host response to plant disease $(7,17)$. In avocado, net $\mathrm{CO}_{2}$ assimilation $(A)$, stomatal conductance of $\mathrm{H}_{2} \mathrm{O}\left(g_{s}\right)$, and transpiration $(E)$ were used previously to monitor stress induced by Phytophthora root rot, caused by Phytophthora cinnamomi (27,29). Xylem sap flow has also been used to assess host response, especially when reduced water transport is implicated in the development of a studied disease $(13,20,37)$. For example, in Wych elm affected by Dutch elm disease (37) and bitternut hickory infected by Ceratocystis smalleyi (20), the dynamics of host water transport and disease development were examined by measuring xylem sap flow.

WI cultivars are most important in commercial avocado production in semitropical and tropical climates, including Florida (6), and one of the most susceptible WI cultivars, Simmonds, was responsible for approximately $35 \%$ of avocado production in Florida (5). Given the limited understandings of how WI and other avocado genotypes respond to laurel wilt, additional information is needed on host attributes that are associated with the disease's development and factors that are related to host tolerance. The primary objective of this study was to examine the physiology of avocado cultivars that differ in susceptibility to laurel wilt, before and after inoculation with $R$. lauricola. Leaf gas exchange and 
xylem sap flow were assessed to determine their relationships with each other and with the temporal development of laurel wilt. Results from this work are discussed regarding the identification of tolerance to this disease.

\section{MATERIALS AND METHODS}

Plant material and study site. Two experiments were conducted with 'Russell' (WI), 'Brogdon' $(\mathrm{M} \times \mathrm{G} \times \mathrm{WI})$, and 'Marcus Pumpkin' (G) avocado cultivars (clonal scions grafted onto 'Waldin' [WI] seedling rootstocks) $(5,26,30)$. In previous work with these cultivars, Russell was most susceptible to laurel wilt, Brogdon was moderately susceptible, and Marcus Pumpkin was least susceptible (26). Plants were obtained from a commercial nursery and grown in a commercial potting medium (40\% Canadian peat, $40 \%$ cypress saw dust, and $20 \%$ cypress chips, by volume) in 11.4-liter pots. The experiments were conducted from January to March 2013 in a greenhouse, located at the University of Florida's Tropical Research and Education Center in Homestead, FL $\left(25.5^{\circ} \mathrm{N}\right.$ and $80.5^{\circ} \mathrm{W}$ ), which had fans and cooling pads to reduce heat load. Air temperature and relative humidity in the greenhouse were recorded above the tree canopies with a StowAway TidbiT sensor/ data logger (Onset, Bourne, MA). Light intensity (solar radiation) was continuously recorded and downloaded from an automated weather station of the Florida Automated Weather Network (http:// fawn.ifas.ufl.edu/station/station.php?id=440) located $400 \mathrm{~m}$ from the greenhouse. Daily mean light intensities in the study were recorded as hourly summaries over an entire day, calculated as $\left[\mathrm{W} \mathrm{m} \mathrm{m}^{-2} / 24(\mathrm{~h})\right] \times 0.6$ (proportion of ambient light that was transmitted into the greenhouse). During the experiments, mean daily temperatures fluctuated between 12 and $30^{\circ} \mathrm{C}$, relative humidities fluctuated between 50 and $95 \%$, and light intensities fluctuated between 48 and $132 \mathrm{~W} \mathrm{~m}^{-2}$ (Fig. 1).

Host inoculation. An isolate of $R$. lauricola from prior studies on avocado was used in both experiments (CBS 127349) $(11,12,25,26)$. Plants were inoculated by drilling, $100 \mathrm{~mm}$ above the graft union, four holes ( $2 \mathrm{~mm}$ in diameter and $4 \mathrm{~mm}$ deep) at $45^{\circ}$ downward angles and equidistant locations around the stem. Into

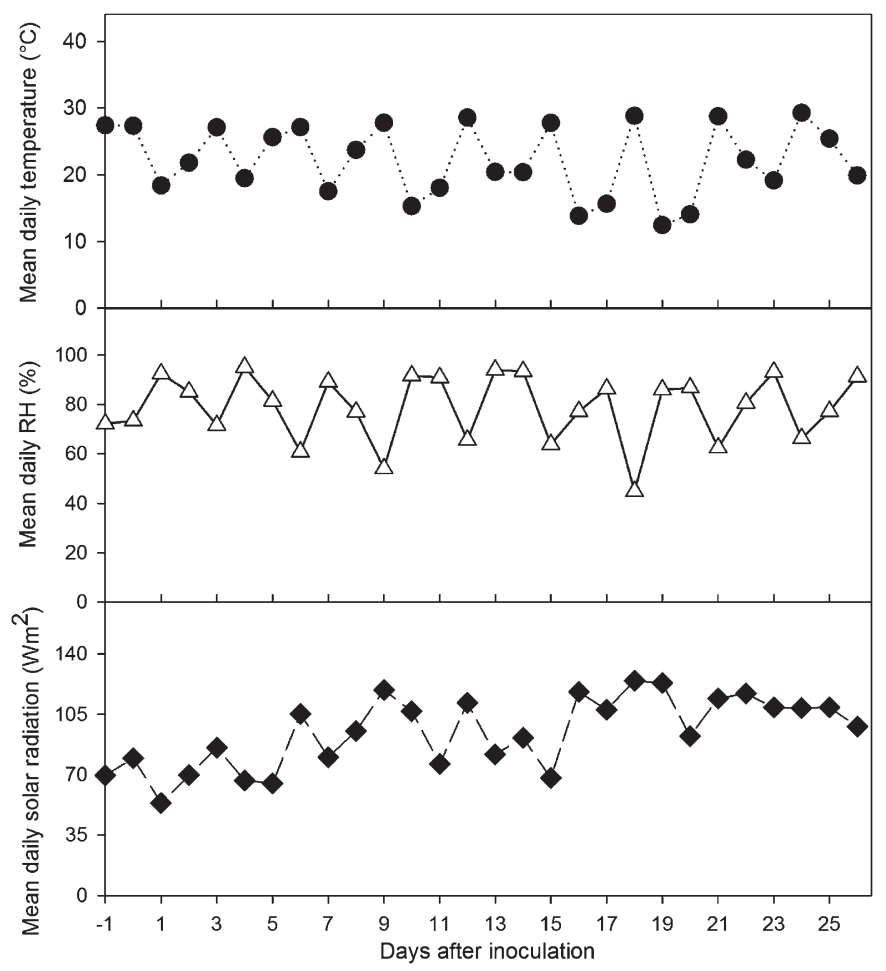

Fig. 1. Mean daily temperature, relative humidity $(\mathrm{RH})$, and solar radiation in the glasshouse during the first experiment. each hole was pipetted $25 \mu$ of a suspension containing 750 conidia, for a total of 3,000 conidia/plant. Holes were wrapped in Parafilm immediately after inoculation.

Leaf gas exchange. $A, g_{s}$, and $E$ were measured with a CIRAS2 portable gas analyzer (PP Systems, Amesbury, MA) at a lightsaturated photosynthetic photon flux of $1,000 \mu \mathrm{mol}$ quanta $\mathrm{m}^{-2} \mathrm{~s}^{-1}$, a reference $\mathrm{CO}_{2}$ concentration in the leaf cuvette of $375 \mu \mathrm{mol} \mathrm{CO}$

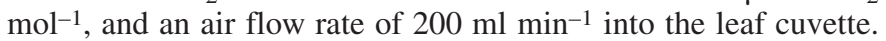
Leaf gas exchange measurements were taken on two recently matured leaves on each tree between $0900 \mathrm{~h}$ and $1200 \mathrm{~h}$ on Mondays, Wednesdays, and Fridays, beginning 1 day before inoculation ( $-1 \mathrm{DAI})$ through the end of each experiment. Leaf water use efficiency (WUE) was calculated as $A / E$.

Xylem sap flow. Xylem sap flow rates were monitored continuously in each plant and data were recorded at hourly intervals with a Dynagage Flow 32-1K Sap Flow System (Dynamax, Inc., Houston) beginning -1 DAI through the end of each experiment. The system used the steady-state heat balance method, in which a thin flexible heater and heat sensors were wrapped around a small segment of the stem and sap flow was calculated from heat fluxes in the xylem (2). To compare rates for the different cultivars, mean hourly rates and daily rates were calculated on a per-plant basis.

Disease assessment. In both experiments, trees were rated daily for severity of external symptoms of laurel wilt (based on the percentage of the canopy that was symptomatic) and, at the end of experiments, plants were destructively sampled to rate disease internally (percent sapwood discoloration). A synoptic 1-to-10 rating scale was used, wherein $1=$ no visual symptoms and $10=$ the entire tree or all sapwood had symptoms $(10,26)$. At the end of experiments, the presence or absence of $R$. lauricola was assessed $5 \mathrm{~cm}$ below and 5 and $100 \mathrm{~cm}$ above the inoculation point, as described previously (26). To determine internal disease development and pathogen recovery before replicates of Russell were completely necrotic, the first experiment was terminated 27 DAI and the second 22 DAI.

Experimental design and data analyses. Treatments (cultivars) were arranged in a completely randomized design with four single-tree inoculated and one noninoculated replication for each cultivar. Leaf gas exchange ( $A, E, g_{s}$, and WUE), xylem sap flow, and external and internal disease data were collected for the four inoculated trees and the noninoculated checks for each cultivar. Leaf gas exchange, xylem sap flow, and external disease data were analyzed by repeated-measures analysis of variance (ANOVA); internal disease data were analyzed by one-way ANOVA and a Duncan-Waller K-ratio test; and preinoculation sap flow was correlated with external disease rating by Pearson product-moment correlation using the SAS statistical software package (SAS 9.1; SAS Institute, Cary, NC).

\section{RESULTS}

Rank differences in disease development on and physiological responses of the three cultivars were similar in experiments 1 and 2 (i.e., Marcus Pumpkin was slightly affected, Brogdon was moderately affected, and Russell was severely affected by laurel wilt) (Table 1) (data not shown). Because the temporal development

TABLE 1. Mean external and internal development of laurel wilt symptoms in trees of different avocado cultivars ${ }^{\mathrm{z}}$

\begin{tabular}{lccccc}
\hline & \multicolumn{2}{c}{ Experiment 1} & & \multicolumn{2}{c}{ Experiment 2} \\
\cline { 2 - 3 } \cline { 5 - 6 } Cultivar & External & Internal & & External & Internal \\
\hline Russell & $8.75 \mathrm{a}$ & $8.5 \mathrm{a}$ & & $9.25 \mathrm{a}$ & $9.25 \mathrm{a}$ \\
Brogdon & $4 \mathrm{~b}$ & $5 \mathrm{~b}$ & & $4.5 \mathrm{~b}$ & $6.75 \mathrm{~b}$ \\
Marcus Pumpkin & $1.5 \mathrm{~b}$ & $2.5 \mathrm{~b}$ & & $2.25 \mathrm{~b}$ & $4.25 \mathrm{c}$ \\
\hline
\end{tabular}

${ }^{\mathrm{z}}$ Means followed by the same letter in a column are not significantly different, according to the Duncan-Waller K-ratio test $(P<0.05)$. 
of symptoms differed between the experiments, it was not possible to combine results. Unless indicated, results for experiment 1 are discussed below.

Symptom development. By 15 DAI, external symptoms of laurel wilt began to develop on all cultivars (Figs. 2-5). For the susceptible WI Russell, symptoms progressed rapidly to a mean external rating of 8.8 by 19 DAI. As expected, less disease developed on Brogdon, which reached a mean maximum severity of 3.5, and the lowest amount of disease developed on Marcus Pumpkin (mean severity of 1.5). From 15 DAI to the end of the experiment (27 DAI), mean daily disease severities were significantly higher for Russell than Brogdon and Marcus Pumpkin. From 11 to 27 DAI, external severities were also higher for Brogdon than Marcus Pumpkin, although daily differences between these cultivars were not significant. Mean internal severities at the end

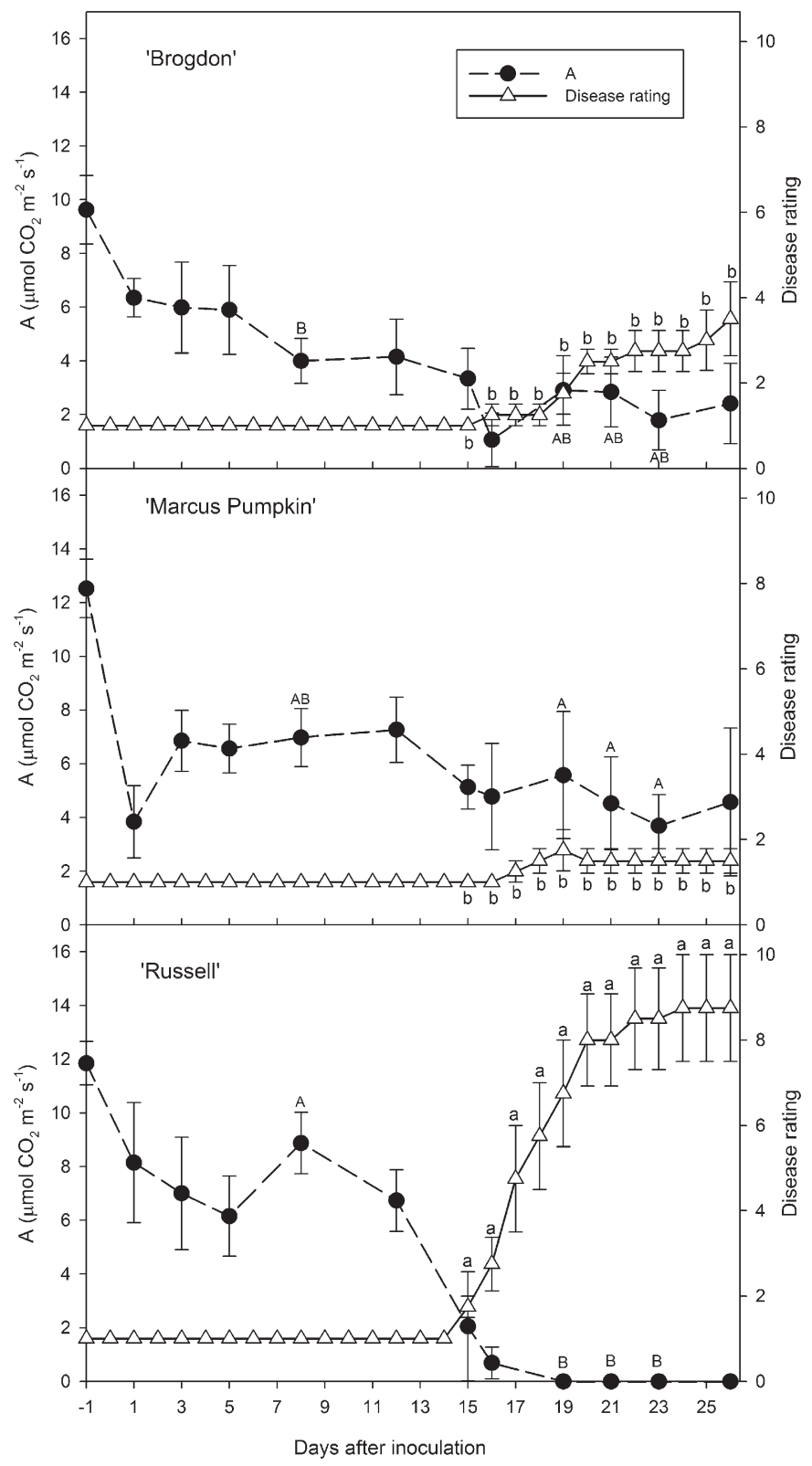

Fig. 2. Net $\mathrm{CO}_{2}$ assimilation $(A)$ and external severity of laurel wilt on Brogdon, Marcus Pumpkin, and Russell avocado trees before (-day) and after (+days) inoculation with Raffaelea lauricola. Data are means \pm standard error for four trees of each cultivar. Different uppercase letters indicate significant differences in $A$ among cultivars and different lowercase letters indicate significant differences in disease severity among cultivars according to a repeatedmeasures analysis of variance $(P \leq 0.05)$. No letters indicate that there were no significant differences among cultivars $(P>0.05)$. of experiment 1 and daily external severities in experiment 2 reflected the above statistical trend but significant internal severities for each cultivar were noted only at the end of experiment 2 (Table 1). In both experiments, $R$. lauricola was recovered from sapwood of all inoculated but no noninoculated trees.

Leaf gas exchange. There was a dip in mean $A, g_{s}$, and $E$ values in each cultivar immediately after inoculation (i.e., from -1 to 1 DAI) (Figs. 2-4). This was presumably due to the effect of drilling into trees during the inoculation process, because this did not occur in noninoculated control trees (Fig. 6), and transient reductions in leaf gas exchange variables are detected in several tree species, including avocado, immediately after girdling (B. Schaffer, unpublished data). Mean $A, g_{s}$, and $E$ declined significantly in all inoculated cultivars by the end of an experiment (Figs. 2-4) (data not shown), whereas there was no decline in any of these variables in

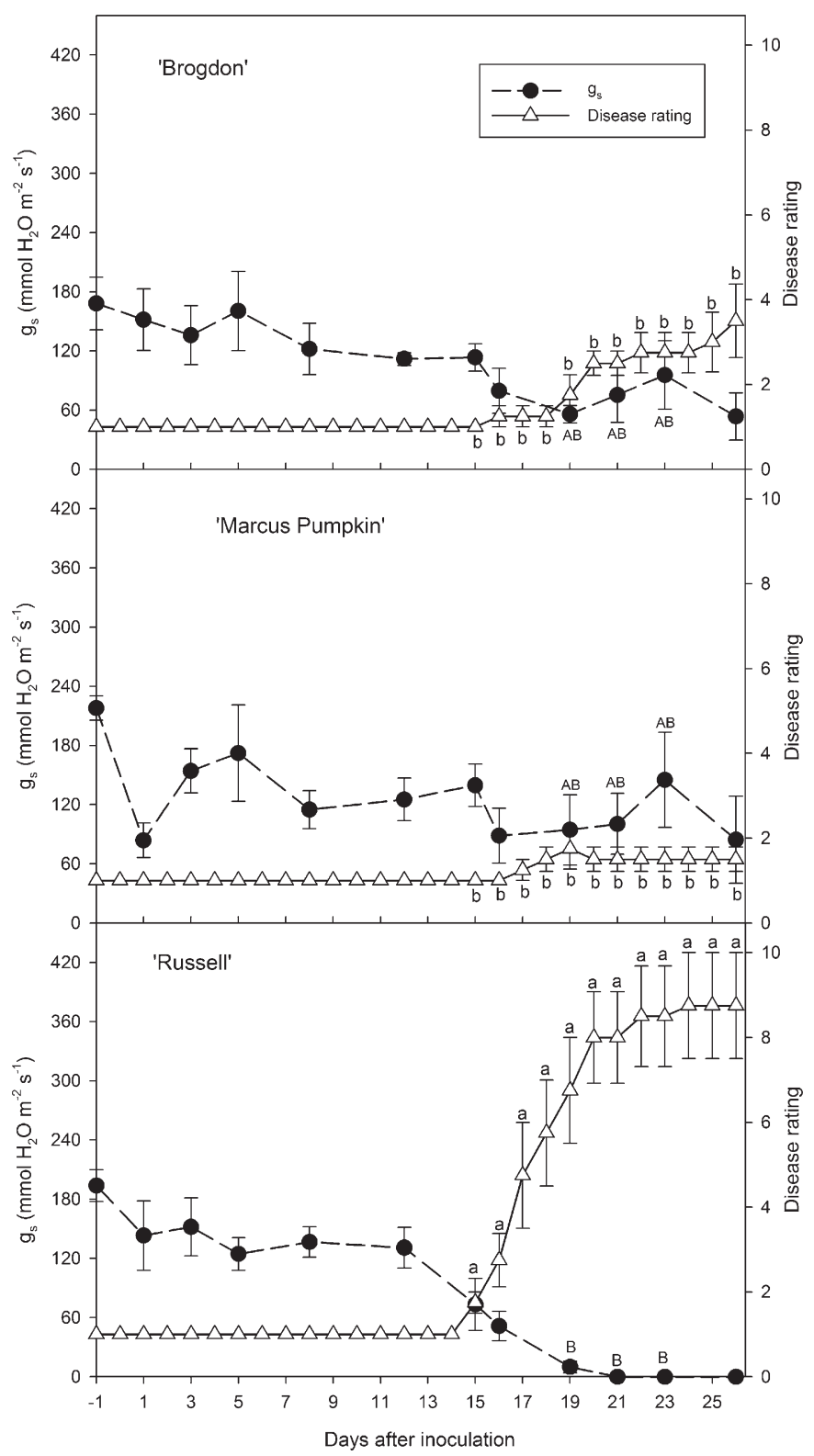

Fig. 3. Stomatal conductance $\left(g_{s}\right)$ and external severity of laurel wilt on Brogdon, Marcus Pumpkin, and Russell avocado trees before (-day) and after (+days) inoculation with Raffaelea lauricola. Data are means \pm standard error for four trees of each cultivar. Different uppercase letters indicate significant differences in $g_{s}$ among cultivars and different lowercase letters indicate significant differences in disease severity among cultivars according to a repeatedmeasures analysis of variance $(P \leq 0.05)$. No letters indicate that there were no significant differences among cultivars $(P>0.05)$. 
the noninoculated trees (Fig. 6) (data not shown). Reductions were greatest in Russell $\left(A, g_{s}\right.$, and $E$ were 0 by $21 \mathrm{DAI}$ in experiment 1$)$ and lowest in Marcus Pumpkin. A was significantly lower in Russell than Marcus Pumpkin at 8, 19, 21, and 23 DAI, whereas there were no significant differences between Brogdon and the other cultivars on these dates (Fig. 2). Significantly lower $g_{s}$ was observed in Russell than in the other cultivars at 19,21, and 23 DAI, and there was no significant difference in $g_{s}$ between the other two cultivars on these dates (Fig. 3). At 15, 19, 21, and 23 DAI, $E$ was also significantly lower in Russell than Marcus Pumpkin, whereas there was no difference in $E$ between Brogdon and the other cultivars on these dates (Fig. 4). WUE declined after inoculation in all cultivars; however, this was most pronounced in Russell, in which WUE was 0 by 19 DAI (Fig. 5). WUE was significantly lower in
Russell than in the other two cultivars by 21 DAI and was significantly lower in Russell than Marcus Pumpkin at 8, 11, 19, 21, and 23 DAI.

Xylem sap flow. Prior to inoculation and for 11 DAI, mean daily sap flow rates were significantly higher in Russell than in Brogdon and Marcus Pumpkin (Fig. 7). Before inoculation and until the end of the experiment, there were no significant differences in mean daily sap flow between Brogdon and Marcus Pumpkin. Mean rates did not decline in these cultivars after inoculation but declined rapidly in Russell from 9 to 15 DAI (Fig. 7); this decline was significant by 11 DAI, 4 days before visible symptoms of the disease appeared (data not shown). Mean daily xylem sap flow rate prior to inoculation ( $-1 \mathrm{DAI})$ was positively correlated with external disease ratings at the end of experiment $1(r=0.46)$.

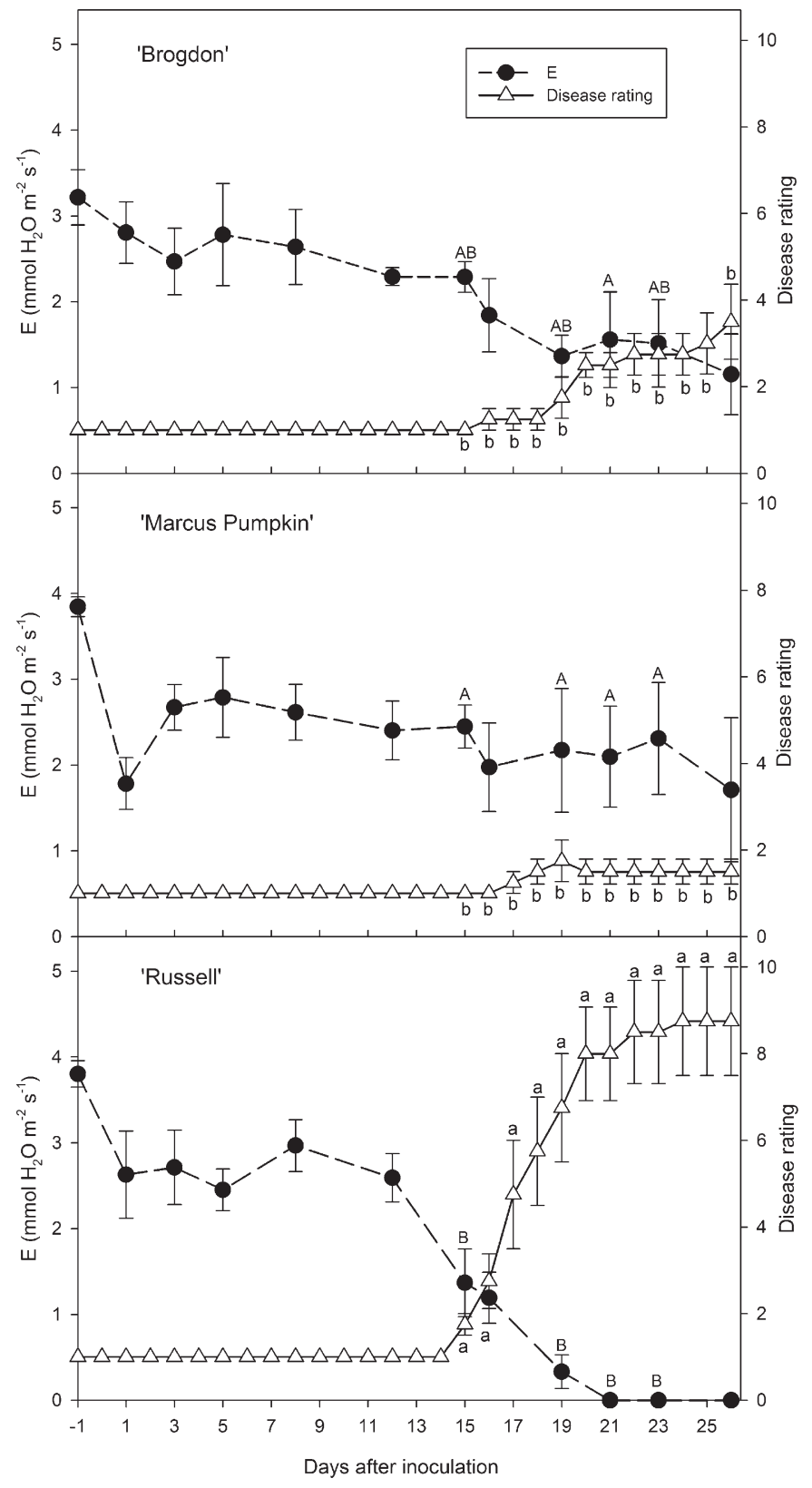

Fig. 4. Transpiration $(E)$ and external severity of laurel wilt on Brogdon, Marcus Pumpkin, and Russell avocado trees before (-day) and after (+days) inoculation with Raffaelea lauricola. Data are means \pm standard error for four trees of each cultivar. Different uppercase letters indicate significant differences in E among cultivars and different lowercase letters indicate significant differences in disease severity among cultivars according to a repeatedmeasures analysis of variance $(P \leq 0.05)$. No letters indicate that there were no significant differences among cultivars $(P>0.05)$.

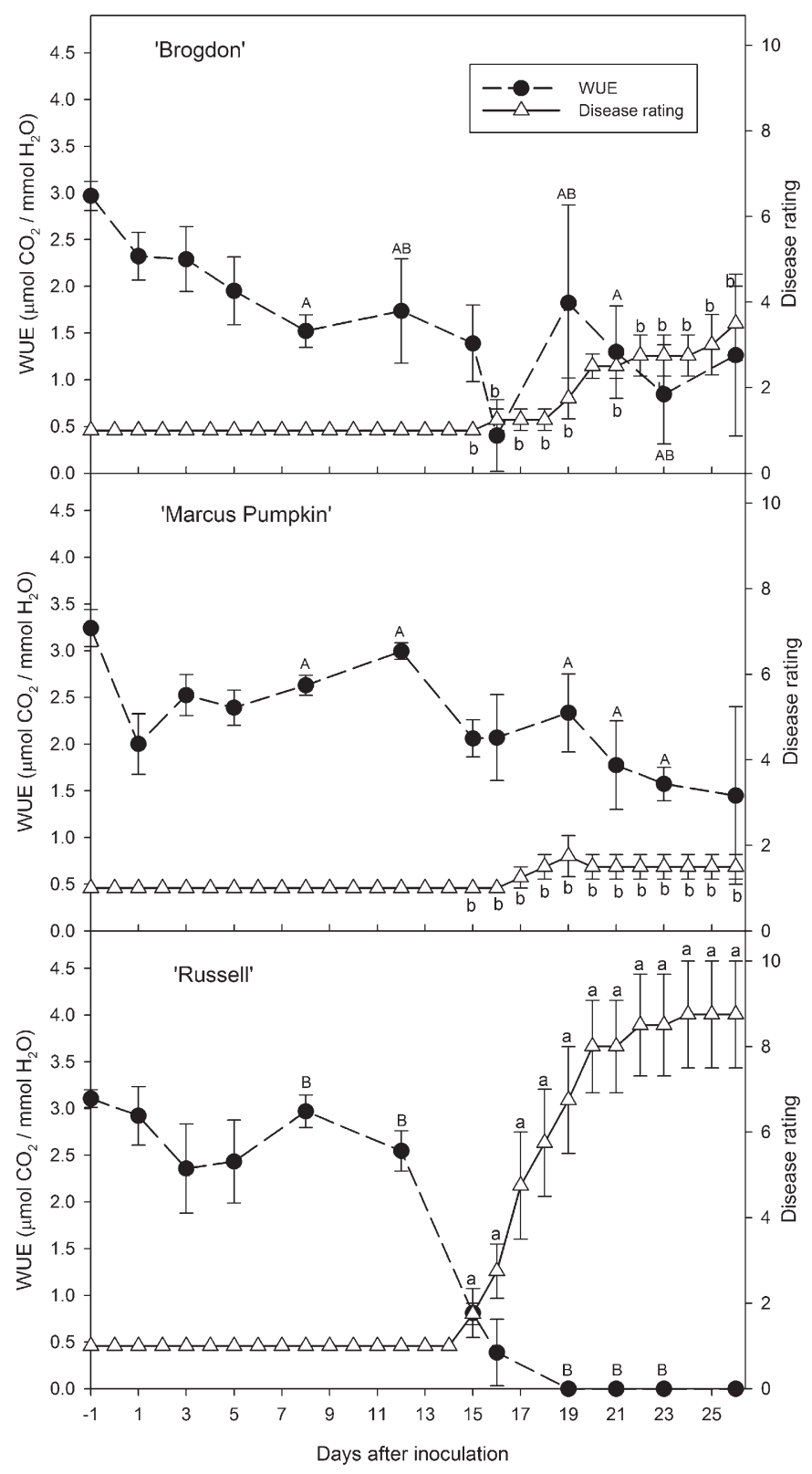

Fig. 5. Water use efficiency (WUE) and external severity of laurel wilt on Brogdon, Marcus Pumpkin, and Russell avocado trees before (-day) and after (+days) inoculation with Raffaelea lauricola. Data are means \pm standard error for four trees of each cultivar. Different uppercase letters indicate significant differences in WUE among cultivars and different lowercase letters indicate significant differences in disease severity among cultivars according to a repeated-measures analysis of variance $(P \leq 0.05)$. No letters indicate that there were no significant differences among cultivars $(P>0.05)$. 
Before inoculation and during daylight, mean hourly sap flow rates were much greater in Russell than in the other cultivars (Fig. 8). For all cultivars, diurnal fluctuations in mean sap flow were associated with diurnal changes in incident solar radiation, ambient temperature, and relative humidity (Fig. 9). Mean hourly sap flow rates remained higher in Russell than in the other cultivars until 17 DAI but only during the morning, because hourly rates declined to levels found in the other cultivars by the afternoon (Fig. 8). Mean hourly sap flow rates in Russell were lower than in the other cultivars because more severe disease developed in this cultivar 24 to 27 DAI (Fig. 8). That sap flow differences were not statistically significant among cultivars at 24 to 27 DAI was the result of variation in the data caused by a single plant (replication) of Russell that did not develop severe disease (Fig. 10).

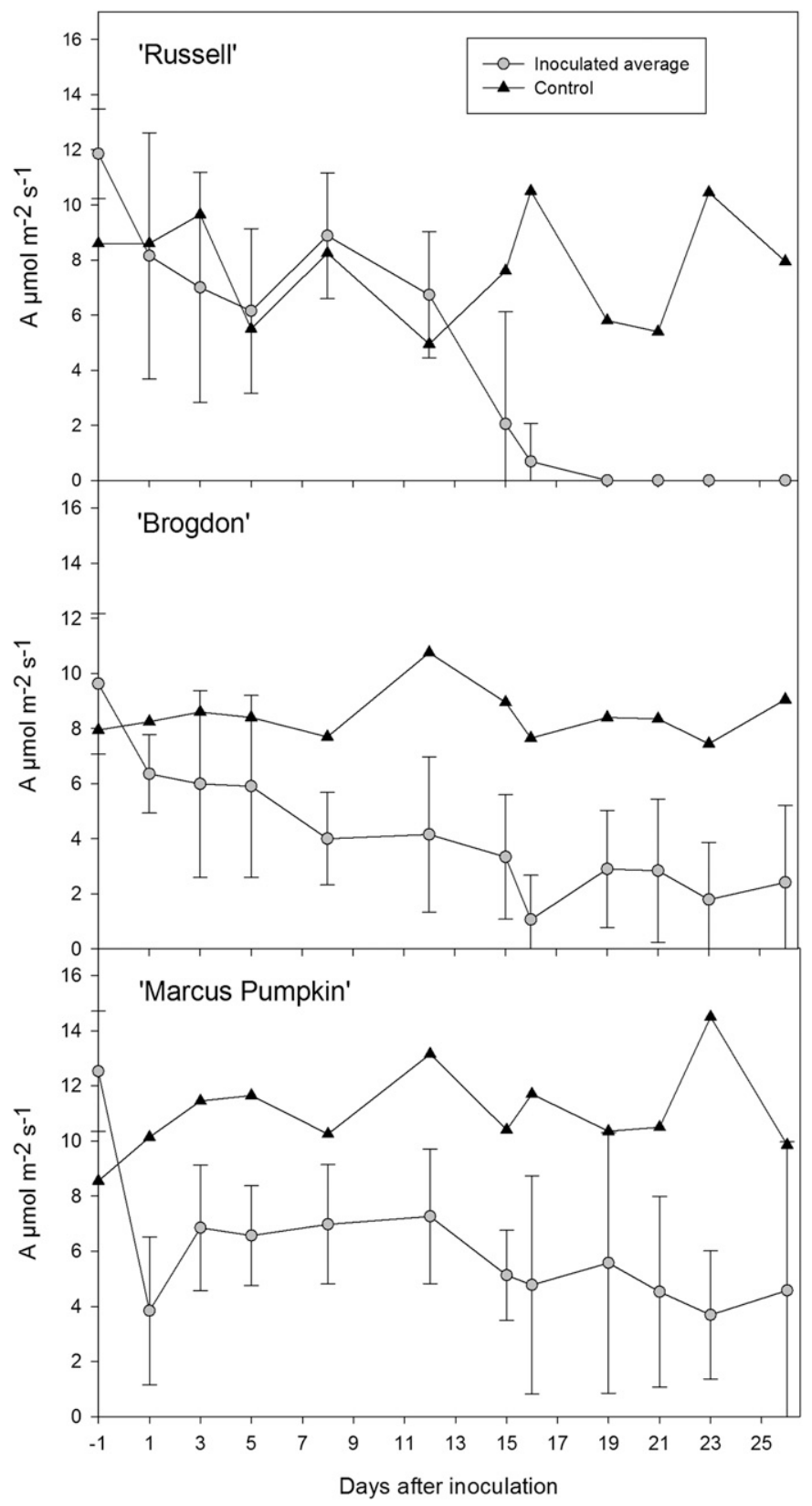

Fig. 6. Net $\mathrm{CO}_{2}$ assimilation (A) for individual, noninoculated control Marcus Pumpkin, Brogdon, and Russell avocado trees $(\boldsymbol{\Delta})$ compared with means for inoculated trees of the same cultivars in the first experiment (shaded circle). The $\mathrm{X}$-axis indicates days before (-day) and after (+days) inoculation with Raffaelea lauricola. Note that the dip in mean $A$ that occurred from 1 day before ( -1 day) to soon after inoculation (+1 day) did not occur in the noninoculated control trees, which were not wounded (drilled) for inoculation.

\section{DISCUSSION}

In the present studies, Russell was more susceptible to laurel wilt than Brogdon or Marcus Pumpkin. These results agree with those from prior work, in which the same rank order of susceptibility was noted for these cultivars as well as the generally higher susceptibility of the WI race (26). However, this is the first detailed report of physiological responses of avocado to laurel wilt, and how these responses relate to the development of symptoms of and susceptibility to this disease. In general, there was a close relationship between the development of external symptoms of laurel wilt and $A, g_{s}, E$, WUE, and mean daily sap flow in Russell; symptoms on this cultivar were always associated with decreases in these parameters. Significantly greater mean disease and lower mean $A$, $g_{s}, E$, WUE, and sap flow rates were often detected in Russell by 15 DAI compared with Brogdon and Marcus Pumpkin.

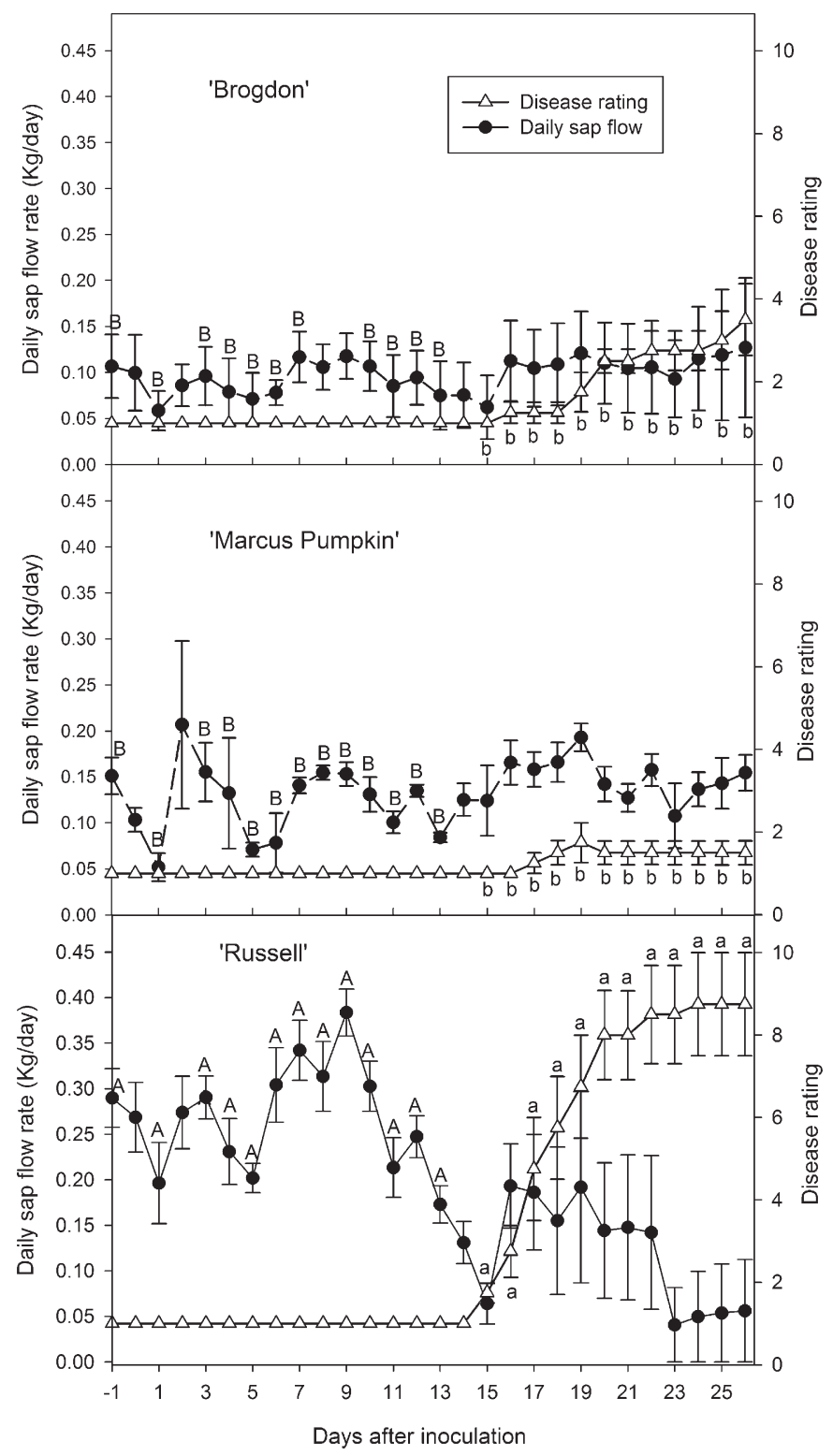

Fig. 7. Mean daily xylem sap flow and external severity of laurel wilt on Brogdon, Marcus Pumpkin, and Russell avocado trees before (-day) and after (+days) inoculation with Raffaelea lauricola. Data are means \pm standard error for four trees of each cultivar. Different uppercase letters indicate significant differences in xylem sap flow among cultivars and different lowercase letters indicate significant differences in disease severity among cultivars according to a repeated-measures analysis of variance $(P \leq 0.05)$. No letters indicate that there were no significant differences among cultivars $(P>0.05)$. 


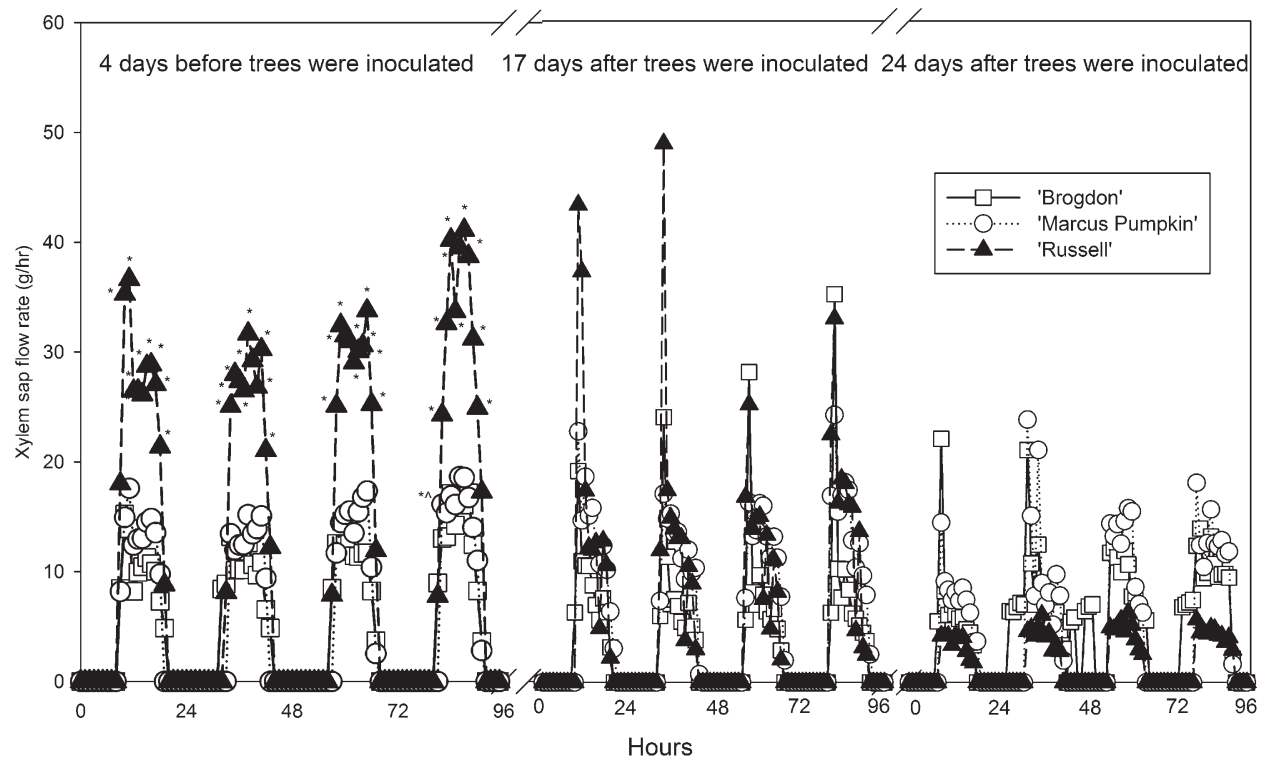

Fig. 8. Mean hourly xylem sap flow for Brogdon, Marcus Pumpkin, and Russell avocado trees 3 days before inoculation with Raffaelea lauricola, immediately after symptoms developed (17 to 19 days after inoculation), and at the end of the experiment (24 days after inoculation). Data are means of four trees of each cultivar. An asterisk indicates a significant difference between Russell and the other cultivars but no significant difference between Marcus Pumpkin and Brogdon, and a caret indicates significant differences between Russell and Marcus Pumpkin but no significant difference between the other cultivars according to a repeatedmeasures analysis of variance $(P \leq 0.05)$. No letters indicate that there were no significant differences among cultivars $(P>0.05)$.

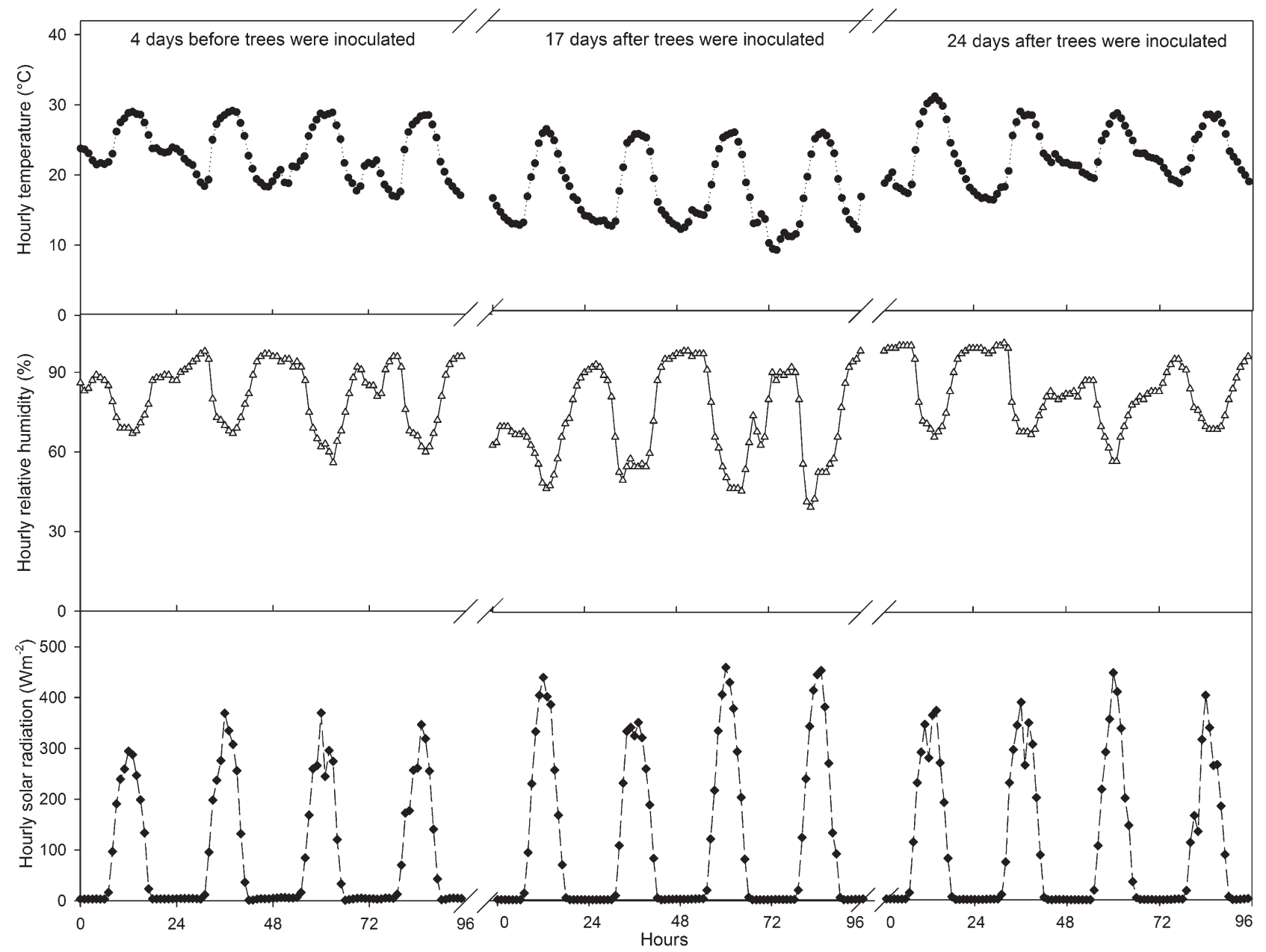

Fig. 9. Mean hourly temperature, relative humidity (RH), and solar radiation (SolRad) at times corresponding to the hourly xylem sap flow rates in Figure 8 . 
As might be expected, symptom development has been associated with reduced water transport in diseases of other trees in which the xylem is affected. Wych elm affected by Dutch elm disease (caused by Ophiostoma novo-ulmi) (37), bitternut hickory affected by hickory decline (C. smalleyi) (20), Quercus spp. affected by Japanese oak wilt (R. quercivora) (16), and Lithocarpus densiflorus affected by sudden oak death ( $P$. ramorum) (21) all exhibit reduced xylem function which is, in turn, correlated with symptom development. For example, Park et al. (20) detected an inverse relationship between xylem sap flow and cankers caused by C. smalleyi. They hypothesized that tylose formation that was associated with cankers was responsible for reduced water transport in affected trees, and that multiple cankers and xylem dysfunction that was associated with them contributed to crown wilt and decline development in bitternut hickory.

Although additional avocado cultivars should be tested, we hypothesize that a scion's susceptibility to laurel wilt is related to its ability to conduct water. Preinoculation sap flow rates were significantly greater in the most susceptible cultivar, Russell, compared with Brogdon and Marcus Pumpkin, and preinoculation rates for all trees were related to disease severity at the end of an experiment. Whether sap flow rates are a general predictor of laurel wilt susceptibility in avocado and whether low rates might predict tolerance to the disease should be examined. There is a positive relationship between tree size and the severity of laurel wilt that develops naturally or after artificial inoculation on avocado (26) (R. C. Ploetz, unpublished). Although greater and more consistent disease develops when large field-grown trees are inoculated, useful information is still obtained on the tolerance of different avocado genotypes when smaller trees are used (22). A trait with which tolerance could be selected in such plants would facilitate improvement of this important fruit crop.

In long-term studies to develop elm trees that resist Dutch elm disease, vessel size and sap flow were reported to be key factors in the susceptibility of Ulmus minor and Ulmus hybrids $(32,33,38)$. Susceptible trees had significantly wider and longer vessels than those that resisted the disease (38). Solla and Gil (33) hypothesized that vessel diameters and sap flow affected the dispersal of $O$. novo-ulmi in the elm host, and Venturas et al. (38) suggested that xylem structure restricted the pathogen's spread in resistant elms. Additional work is needed on the relationship between laurel wilt tolerance in avocado and sap flow and other xylem-associated attributes, because it may facilitate the identification of tolerant genotypes.

In prior studies on Phytophthora root rot of avocado, leaf gas exchange parameters indicated host stress before plants exhibited external symptoms of this disease (wilting and defoliation) (29). In the present study, leaf gas exchange decreased only when or shortly after external symptoms of laurel wilt became evident on Russell. In work on the elm-O. novo-ulmi system, $g_{s}$ was significantly greater in susceptible genotypes soon after inoculation, which Venturas et al. (38) indicated facilitated systemic movement of the pathogen. Such a response was not noted in the present study. Clearly, additional work is needed to determine the extent to which laurel wilt resembles other diseases of avocado or other tree species, and whether comparisons with these diseases shed useful light on laurel wilt.

Artificial inoculation with $R$. lauricola consistently produces symptoms of laurel wilt on host trees $(10,26)$, has provided important information on host range (9), has enabled microscopic observations of the host-pathogen interaction (11), and has demonstrated that tree size (stem diameter) was positively correlated with disease development (26). However, variation in disease response has been evident on specific avocado cultivars in experimental work and in commercial production. For example, in the above tree size experiments, only $34 \%$ of the variation in laurel wilt severity on Simmonds was related to stem diameter (26).

Causes for the above variation are not known but the heterogeneous nature of the rootstocks used in Florida may be a contributing factor. Commercial production of avocado in Florida occurs with trees that are clonal scions grafted onto seedling rootstocks. Seedlings of avocado are usually hybrids because the species preferentially outcrosses. Although variation would be expected in seedling rootstocks and, perhaps, in clonal scions on which they are grafted, it is not known whether seedling rootstocks influence laurel wilt development in clonal avocado scions.

Rootstocks significantly affect sap flow in different perennial fruit crops due to discontinuities in the graft union area, effects on stomatal conductance, and the vigor of the rootstocks $(1,15,19,34,35)$. For example, low vigor or dwarfing rootstocks of apple, kiwifruit, and peach also had low levels of hydraulic conductance $(4,18,31)$. Fassio et al. (8) noted the same trend when 'Hass' scions were grafted on different clonal avocado rootstocks.

The effects of different rootstocks are recognized in avocado $(3,6)$. Rootstocks tolerant to Phytophthora root rot, which have been developed and used for decades, are most notable; however, other effects and objectives have been noted. These include rootstocks that tolerate calcareous and saline soils, and others that affect the postharvest development of anthracnose and internal disorders on avocado fruit $(3,6,40)$.

We propose that rootstocks might also influence the susceptibility of a given avocado scion to laurel wilt. Fassio et al. (8) reported that xylem sap flow rates were lower for 'Toro Canyon' than 'Duke 7' clonal avocado rootstocks, and that sap flow rates in Hass scions were also lower when grafted to Toro Canyon compared with Duke 7. Given the relationship between preinoculation sap flow rate and laurel wilt susceptibility that was evident in the present study and

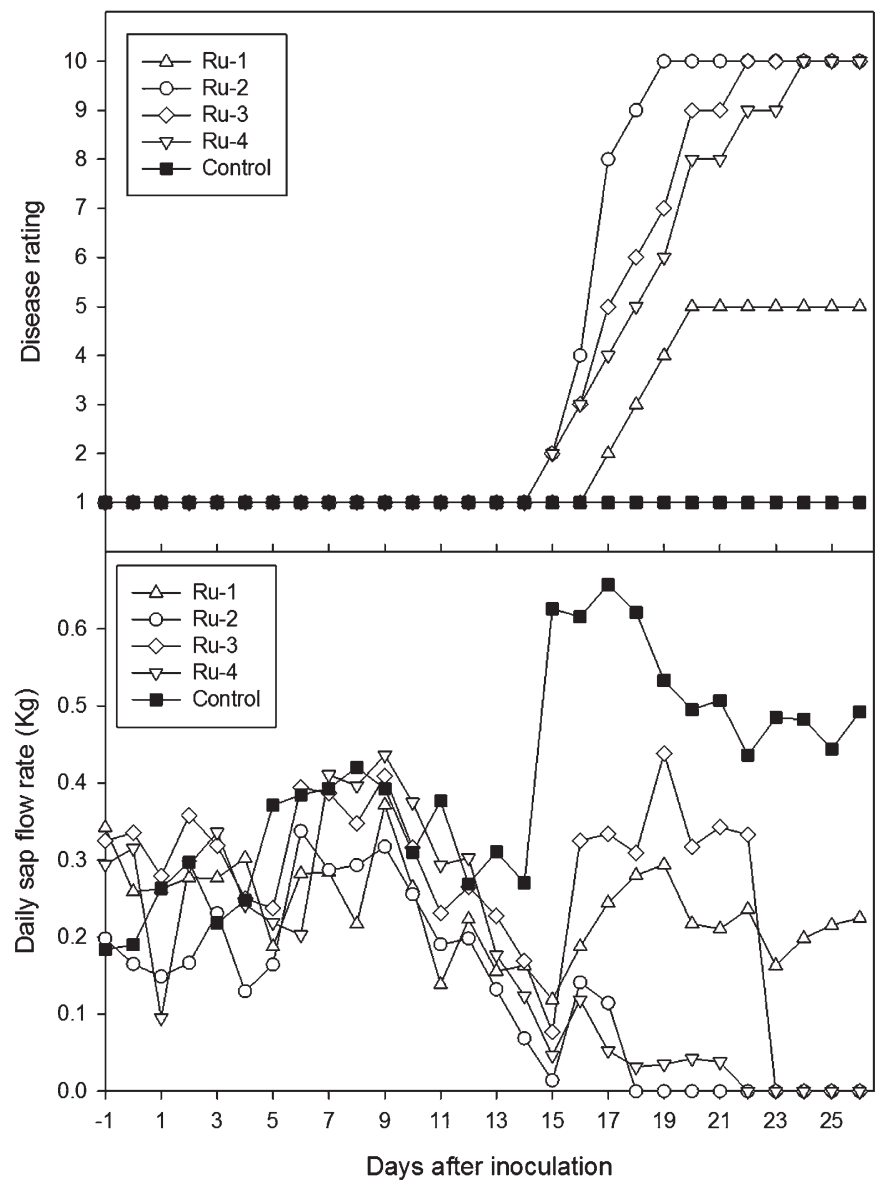

Fig. 10. External severity of laurel wilt on individual trees (replications) of Russell avocado trees not inoculated (control) or inoculated with Raffaelea lauricola (Ru-1 to $\mathrm{Ru}-4)$ (top), and mean daily sap flow for the corresponding trees (bottom). Days are before (-) and after inoculation. By the end of the experiment, tree $1(\mathrm{Ru}-1)$ was the only inoculated tree that did not die and had sap flow. 
the general influence of rootstocks on scion performance, the susceptibility of different avocado scions to laurel wilt could be affected by rootstocks that influence hydraulic performance in the scion. Furthermore, variation in laurel wilt response that has been observed in trees with seedling rootstocks (26) might be reduced if clonal rootstocks were used. Work to investigate these possibilities is warranted, because additional tools are needed to manage this destructive disease.

\section{ACKNOWLEDGMENTS}

We thank S. Inch for work on an unreported initial sap flow experiment. This work was supported, in part, by NIFA grant 2009-51181-05915.

\section{LITERATURE CITED}

1. Atkinson, C., Else, M., Taylor, L., and Webster, A. 2001. The rootstock graft union: A contribution to the hydraulics of the worked fruit tree. Acta Hortic. 557:117-122.

2. Baker, J. M., and Nieber, J. L. 1989. An analysis of the steady-state heat balance method for measuring sap flow in plants. Agric. For. Meteorol. 48:93-109.

3. Ben Ya'acov, A., and Michelson, E. 1995. Avocado rootstocks. Hortic. Rev. (Am. Soc. Hortic. Sci.) 17:381-429.

4. Clearwater, M., Lowe, R., Hofstee, B., Barclay, C., Mandemaker, A., and Blattmann, P. 2004. Hydraulic conductance and rootstock effects in grafted vines of kiwifruit. J. Exp. Bot. 55:1371-1382.

4a. Campbell, A. F. 2014. Characterizing pathogen-vector-host interactions in laurel wilt. Ph.D. thesis. Univ Florida, Gainesville. 136 pp.

5. Crane, J. H., Balerdi, C. F., and Maguire, I. 2007. Avocado growing in the Florida home landscape. Online publication. Univ. Fla. IFAS Ext. Serv. Publ. Circ. 1034. http://edis.ifas.ufl.edu/mg213

6. Crane, J. H., Douhan, G., Faber, B. A., Arpaia, M. L., Bender, G. S., Balerdi, C. F., and Barrientos-Priego, A. F. 2013. Cultivars and rootstocks. Pages 200-233 in: The Avocado: Botany, Production and Uses, 2nd ed. B. Schaffer, B. N. Wolstenholme, and A. W. Whiley, eds. CAB International Publishing, Wallingford, UK.

7. Durkovic, J., Canova, I., Lagana, R., Kucerova, V., Moravcık, M., Priwitzer, T., Urban, J., Dvorak, M., and Krajnakova, J. 2013. Leaf trait dissimilarities between Dutch elm hybrids with a contrasting tolerance to Dutch elm disease. Ann. Bot. 111:215-227.

8. Fassio, C., Heath, R., Arpaia, M. L., and Castro, M. 2009. Sap flow in 'Hass' avocado trees on two clonal rootstocks in relation to xylem anatomy. Sci. Hortic. 120:8-13.

9. Fraedrich, S. W., Harrington, T. C., Rabaglia, R. J., Ulyshen, M. D., Mayfield, A. E., III, Hanula, J. L., Eickwort, J. M., and Miller, D. R. 2008. A fungal symbiont of the redbay ambrosia beetle causes a lethal wilt in redbay and other Lauraceae in the southeastern USA. Plant Dis. 92: 215-224.

10. Hughes, M. A., Inch, S. A., Ploetz, R. C., Er, H. L., van Bruggen, A. H. C., and Smith, J. A. Responses of swamp bay, Persea palustris, and avocado, Persea americana, to the laurel wilt pathogen, Raffaelea lauricola. For. Pathol. (In press.)

11. Inch, S., Ploetz, R., Held, B., and Blanchette, R. 2012. Histological and anatomical responses in avocado, Persea americana, induced by the vascular wilt pathogen, Raffaelea lauricola. Botany 90:627-635.

12. Inch, S. A., and Ploetz, R. C. 2012. Impact of laurel wilt, caused by Raffaelea lauricola, on xylem function in avocado, Persea americana. For. Pathol. 42:239-242.

13. Kirisits, T., and Offenthaler, I. 2002. Xylem sap flow of Norway spruce after inoculation with the blue-stain fungus Ceratocystis polonica. Plant Pathol. 51:359-364.

14. Lahav, E., and Lavi, U. 2013. Genetics and breeding. Pages 51-85 in: The Avocado: Botany, Production and Uses, 2nd ed. B. Schaffer, B. N. Wolstenholme, and A. W. Whiley, eds. CAB International Publishing, Wallingford, UK.

15. Massai, R., and Gucci, R. 1997. Transpiration and water relation in three peach $\times$ almond hybrid rootstocks. Acta Hortic. 44:99-106.

16. Murata, M., Yamada, T., and Ito, S. 2005. Changes in water status in seedlings of six species in the Fagaceae after inoculation with Raffaelea quercivora Kubono et Shin-Ito. J. For. Res. 10:251-255.

17. Nogues, S., Cotxarrera, L., Alegre, L., and Trillas, M. I. 2002. Limitations to photosynthesis in tomato leaves induced by Fusarium wilt. New Phytol. 154:461-470.
18. Olien, W. C., and Lakso, A. N. 1986. Effect of rootstocks on apple (Malus domestica) tree water relations. Physiol. Plant. 67:421-430.

19. Olmstead, M., Lang, S., Ewers, F., and Owens, S. 2006. Xylem vessel anatomy of sweet cherries grafted onto dwarfing and non-dwarfing rootstocks. J. Am. Soc. Hortic. Sci. 131:577-585.

20. Park, J.-H., Juzwik, J., and Cavender-Bares, J. 2013. Multiple Ceratocystis smalleyi infections associated with reduced stem water transport in bitternut hickory. Phytopathology 103:565-574.

21. Parke, J. L., Oh, E., Voelker, S., Hansen, E. M., Buckles, G., and Lachenbruch, B. 2007. Phytophthora ramorum colonizes tanoak xylem and is associated with reduced stem water transport. Phytopathology 97: $1558-1567$.

22. Ploetz, R. C., Harrington, T., Hulcr, J., Fraedrich, S., Smith, J. A., Inch, S., Kendra, P., Mayfield, A. E., Hanula, J., Rabaglia, R., Palmateer, A., Pena, J., Eskalen, A., Crane, J., Faber, B., Bostock, R., Harmon, C., Schnell, R., and Wingfield, M. J. 2011. Recovery plan for laurel wilt of avocado (caused by Raffaelea lauricola). National Plant Disease Recovery System. Homeland Security Presidential Directive Number 9 (HSPD-9). Online publication. http://www.ars.usda.gov/research/docs.htm?docid=14271.

23. Ploetz, R. C., Hulcr, J., Wingfield, M., and de Beer, Z. W. 2013. Ambrosia and bark beetle-associated tree diseases: Black Swan events in tree pathology? Plant Dis. 97:856-872.

24. Ploetz, R. C., Peña, J. E., Smith, J. A., and Dreaden, T. J. 2011. Laurel wilt, caused by Raffaelea lauricola, is confirmed in Miami-Dade County, center of Florida's commercial avocado production. Plant Dis. 95:1589.

25. Ploetz, R. C., Perez-Martinez, J. M., Evans, E. A., and Inch, S. A. 2011. Toward fungicidal management of laurel wilt of avocado. Plant Dis. 95: 977-982.

26. Ploetz, R. C., Pérez-Martínez, J. M., Smith, J. A., Hughes, M. C., Dreaden, T. J., Yu, Y., and Inch, S. 2012. Responses of avocado to laurel wilt, caused by Raffaelea lauricola. Plant Pathol. 61:801-808.

27. Ploetz, R. C., and Schaffer, B. 1989. Effects of flooding and Phytophthora root rot on net gas exchange and growth of avocado. Phytopathology 79: 204-208.

28. Schaffer, B., Gil, P. M., Mickelbart, M. V., and Whiley, A. W. 2013. Ecophysiology. Pages 168-199 in: The Avocado: Botany, Production and Uses, 2nd ed. B. Schaffer, B. N. Wolstenholme, and A. W. Whiley, eds. CAB International Publishing, Wallingford, UK.

29. Schaffer, B., and Ploetz, R. C. 1989. Net gas exchange characteristics as indicators of damage thresholds for Phytophthora root rot of flooded and nonflooded avocado. HortScience 24:653-655.

30. Schnell, R. J., Brown, J. S., Olano, C. T., Power, E. J., Krol, C. A., Kuhn, D. N., and Motomayor, J. C. 2003. Evaluation of avocado germplasm using microsatellite markers. J. Am. Soc. Hortic. Sci. 128:881-889.

31. Solari, L. 1., Johnson, S., and Dejong, T. M. 2006. Relationship of water status to vegetative growth and leaf exchange of peach (Prunus persica) trees on different rootstocks. Tree Physiol. 26:1333-1341.

32. Solla, A., and Gil, L. 2002. Xylem vessel diameter as a factor in resistance of Ulmus minor to Ophiostoma novo-ulmi. For. Pathol. 32:123-134.

33. Solla, A., Martín, J. A., Corral, P., and Gil, L. 2005. Seasonal changes in wood formation of Ulmus pumila and U. minor and its relation with Dutch elm disease. New Phytol. 166:1025-1034.

34. Syvertsen, J. P. 1981. Hydraulic conductivity of four commercial citrus rootstocks. J. Am. Soc. Hortic. Sci. 106:378-381.

35. Syvertsen, J. P., and Graham, J. H. 1985. Hydraulic conductivity of roots, mineral nutrition, and leaf gas exchange of citrus rootstocks. J. Am. Soc. Hortic. Sci. 110:865-869.

36. United States Department of Agriculture Forest Service. 2014. Laurel wilt survey 2006-2007. Online publication. http://www.fs.fed.us/r8/foresthealth/ laurelwilt/dist_map.shtml

37. Urban, J., and Dvořák, M. 2013. Occlusion of sap flow in elm after artificial inoculation with Ophiostoma novo-ulmi. Acta Hortic. 991: 301-306.

38. Venturas, M., Lopez, R., Martin, J. A., Gasco, A., and Gil, L. 2014. Heritability of Ulmus minor resistance to Dutch elm disease and its relationship to vessel size, but not to xylem vulnerability to drought. Plant Pathol. 63:500-509.

39. Whiley, A. W., and Schaffer, B. 1994. Avocado. Pages 165-197 in: Environmental Physiology of Fruit Crops, Vol. 2, Subtropical and Tropical Crops. B. Schaffer and P. C. Andersen, eds. CRC Press, Boca Raton, FL.

40. Willingham, S. L., Pegg, K. G., Anderson, J. M., Cooke, A. W., Dean, J. R., Giblin, F. R., and Coates, L. M. 2006. Effects of rootstock and nitrogen fertiliser on postharvest anthracnose development in Hass avocado. Australas. Plant Pathol. 35:619-629. 